\title{
Clinical significance of fluid biomarkers in Alzheimer's Disease
}

\author{
Piotr Lewczuk ${ }^{1,2}$ (D) Marta Łukaszewicz-Zając ${ }^{3} \cdot$ Piotr Mroczko $^{4} \cdot$ Johannes Kornhuber $^{1}$
}

Received: 18 December 2019 / Revised: 21 April 2020 / Accepted: 21 April 2020 / Published online: 8 May 2020

(c) The Author(s) 2020

\begin{abstract}
Abstract The number of patients with Alzheimer's Disease (AD) and other types of dementia disorders has drastically increased over the last decades. AD is a complex progressive neurodegenerative disease affecting about 14 million patients in Europe and the United States. The hallmarks of this disease are neurotic plaques consist of the Amyloid- $\beta$ peptide (A $\beta)$ and neurofibrillary tangles (NFTs) formed of hyperphosphorylated Tau protein (pTau). Currently, four CSF biomarkers: Amyloid beta 42 (A $\beta 42$ ), A $\beta 42 / 40$ ratio, Tau protein, and Tau phosphorylated at threonine 181 (pTau181) have been indicated as core neurochemical AD biomarkers. However, the identification of additional fluid biomarkers, useful in the prognosis, risk stratification, and monitoring of drug response is sorely needed to better understand the complex heterogeneity of AD pathology as well as to improve diagnosis of patients with the disease. Several novel biomarkers have been extensively investigated, and their utility must be proved and eventually integrated into guidelines for use in clinical practice. This paper presents the research and development of CSF and blood biomarkers for $\mathrm{AD}$ as well as their potential clinical significance.

\section{Graphic abstract}

Upper panel: A $\beta$ peptides are released from transmembrane Amyloid Precursor Protein (APP) under physiological conditions (blue arrow). In $\mathrm{AD}$, however, pathologic accumulation of $\mathrm{A} \beta$ monomers leads to their accumulation in plaques (red arrow). This is reflected in decreased concentration of $A \beta 1-42$ and decreased $A \beta 42 / 40$ concentration ratio in the CSF. Lower panel: Phosphorylated Tau molecules maintain axonal structures; hyperphosphorylation of Tau (red arrow) in AD leads
\end{abstract}

Extended author information available on the last page of the article 
to degeneration of axons, and release of pTau molecules, which then accumulate in neurofibrillary tangles. This process is reflected by increased concentrations of Tau and pTau in the CSF.
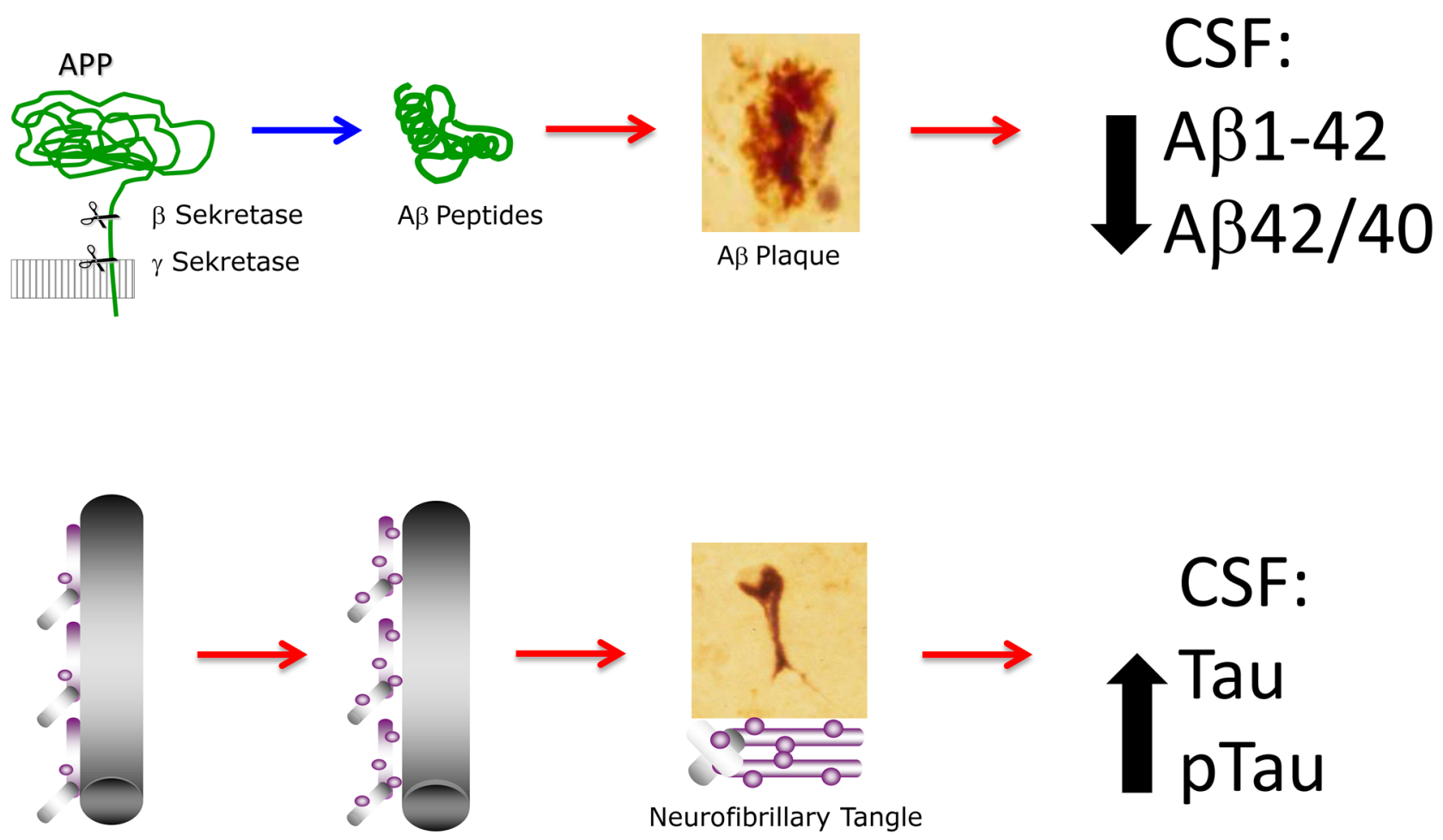

Physiologically phosphorylated Tau
Hyperphosphorylation of Tau

Keywords Alzheimer's Disease $\cdot$ Biomarkers $\cdot$ Cerebrospinal fluid $\cdot$ Amyloid $\cdot$ Tau

\section{Introduction}

Alzheimer's Disease (AD), a complex neurodegenerative disease, is characterized by progressive cognitive impairment to the extend impacting activities of daily living, such as episodic memory loss and alterations in spatial and temporal orientation. The disease is the most common cause of dementia and cognitive decline in subjects over 65 years of age [1]. AD is a growing global public health priority concerns with serious implications for society. It is a condition of mature population, usually doubling in prevalence after age of 65 every 5 years $[2,3]$. Currently about 14 million patients in the USA and Europe are afflicted by AD, and $40 \%$ of this population is over the age of $85[4,5]$. The total costs of this disease and other types of dementia associated with health care, long-term care and hospice were estimated at \$290 billion in 2019 in the United States only. Moreover, the $\mathrm{AD}$ incidence increases with age, thus its prevalence is rising due to ageing of population [3].

Interestingly, European epidemiologic studies show that dementia prevalence was stable from the late 1980s to the early 2000s, which, taken together with increased survival of patients, suggests that incidence of dementia may have decreased during this time interval [6, 7]. It is hypothesized that general lifestyle improvements: early recognition and treatment of diabetes and hypertension (two important risk factors for development of dementia), as well as reduction in prevalence of cigarette smoking might be responsible for this trend [8].

It has been estimated that about 44 million people live with dementia worldwide and this number may triple by 2050 due to the population ageing. The highest increase in the prevalence of dementia is predicted in middle- and lowincome countries $[4,9]$.

Pathologic alterations of AD start in medial temporal lobe and then afflict the areas of neocortex [10,11]; the changes beginning decades before the onset of the clinical symptoms $[3,12]$. AD progresses throughout three stages of pre-symptomatic stage, prodromal stage, such as mild cognitive symptoms, and eventually a symptomatic stage with dementia [13]. Additionally, the MCI (mild cognitive impairment) stage predicts the cognitive dysfunctions of 
dementia. Approximately $10-20 \%$ of MCI patients converted to $A D$ every year [14].

The clinical symptoms is usually preceded by preclinical phase (mainly symptoms-free), thus early diagnosis of $\mathrm{AD}$ remains difficult $[13,15,16]$. AD biomarkers are usually tested when patient has already progressed to the MCI (or later) stage. It has been proved that assessment of cerebrospinal fluid (CSF) may reasonably predict progression of MCI to AD with accuracy of above $80 \%$ [17-19].

Pathophysiology of AD relays on amyloid beta $(\mathrm{A} \beta)$ plaque accumulation and neurofibrillary tangles formed by Tau fibrils as well as neuron and synaptic degeneration, neuroinflammation and glial activation. Extracellular senile plaques, consisting of $A \beta$ peptides and intracellular neurofibrillary tangles, composed of mainly hyperphosphorylated form of Tau (pTau) proteins were proved to be neuropathological features commonly presented in the brains of $\mathrm{AD}$ patients [20]. Thus, these two groups of molecules were found to be the best-validated AD biomarkers.

\section{Cerebrospinal fluid and lumbar puncture: medical and legal perspective}

CSF is generated in the ventricles of the brain, from where it flows around the brain hemispheres, and along the spinal cord, to be ultimately absorbed back to the blood. Since it stays in the direct contact with the brain tissue, it is enormously important source of diagnostic information about physiologic and pathologic processes in the central nervous system (CNS). On the other hand, along the CSF flow path blood proteins diffuse passively into it according to the concentration gradient. This diffusion is known as the blood-CSF barrier (not to be mixed with the blood-brain barrier). Hence, a CSF sample, in most cases collected by lumbar puncture (LP), contains a mixture of proteins originating from the CNS and from the blood. Since it is exclusively produced by the liver and enters the CSF exclusively by passive diffusion, its $\mathrm{CSF} /$ serum concentration quotient $\left(\mathrm{Q}_{\mathrm{Alb}}\right)$ is commonly accepted biomarker of the blood-CSF barrier status. Many other blood proteins, like immunoglobulins (Ig's) diffuse passively to the CSF under normal conditions, but under pathologic conditions, known as neuroinflammation(s), they are also generated in the brain. Since CSF stays in a direct contact to the brain tissue, it is obviously ideal source of biomarkers of brain disorders, like $\mathrm{AD}$ and similar neurodegenerative conditions [16].

Lumbar puncture is a routine medical procedure for the collection of CSF for diagnostic purpose. Each medical activity is regulated by the legal provisions of the country in which it is carried out. This requires physicians to know the basic principles for conducting medical procedures resulting from the legal regulations of a given country. Medical law is different in various jurisdictions, but among the many important provisions that apply to doctors in various countries around the world, one can point out the chief issue, which is of particular importance. This is the legal regulation of the patient's informed consent for medical treatment, such as LPs. The importance of this problem is evidenced by the fact, that in some countries the issue of a patient's decision regarding his medical treatment is regulated in a separate legal act. An example of such a solution is the legal system of England and Wales, where legal regulations regarding this issue are included in the Mental Capacity Act 2005.

This is an extremely important issue regarding the physician's relationship with the patient, because it defines the limits of the rights of the person performing medical activities towards the patient and indicates the basic duties of the physician during the treatment process. On the other hand, the right to consciously decide on treatment protects the patient's basic interests and clearly defines the rights he is entitled to. In various jurisdictions, it is a rule that all medical procedures as well as diagnostic or therapeutic activities require patient consent. This also applies to conducting LPs. This principle may have a different background, depending on the legal culture of the country. It results in the patient's participation in the treatment process. This right is directly related to the physician's duty to inform the patient about his health. Only in such a situation can a person without medical education be able to consciously decide about their treatment.

However, in some situations it is not possible to express patient's informed and voluntary consent. The legal systems of different countries distinguish specific categories of patients who are unable to make an informed decision. This applies among others to people who, due to various types of mental disorders, are recognized by law as being unable to give consent for medical intervention. Although the procedure for determining that a patient is not able to make a decision about their treatment is different in different countries, generally the decision on this case is taken by the court. In such cases, legal provisions designate other people who make such decisions on behalf of the patient. Depending on the situation, these can be parents, legal guardians or for example a person's guardian. Certainly, there are some differences between the legal provisions regarding giving informed consent for medical procedures in different countries, which result, among others, from historical issues [21, 22].

\section{$A \beta$ peptides and $A \beta$ oligomers}

$\mathrm{A} \beta$ peptides are main component of senile plaques, derive via the enzymatic cleavage of $\beta$-amyloid precursor protein (APP) [23]. Thus, $A \beta$ is formed by the sequential cutting of APP via $\beta$-site amyloid precursor protein-cleaving enzyme 1 
(BACE1) as well as $\gamma$-secretase. Subsequently several forms of A $\beta$ peptides are released [24]. In addition, APP might be processed in non-amyloidogenic pathway by $\alpha$-secretase, which leads to the release of soluble APP $\alpha$. Cleavage of APP at different positions by the $\gamma$-secretase leads to release of $\mathrm{A} \beta$ peptides of variable length [25].

The 42-amino acid isoform of $\mathrm{A} \beta 42$ peptide accounts for not more than $5-10 \%$ of the total $A \beta$ peptides in the human CSF [26]. However, A $\beta 42$ is a major component of the plaques in the AD patient brains [27, 28]. Investigations have indicated that the CSF levels of A $\beta 42$ correlate inversely with plaque load, what was found in autopsies or/ and in vivo with positron emission tomography (PET) [29, 30]. The mechanisms leading to the decreased concentrations of A $\beta 42$ in the CSF of AD patients are still unclear. Some authors indicated that it might be a result of the $A \beta 42$ sequestration in $\mathrm{AD}$ plaques with reduced availability to be cleared into the CSF [31]. However, reduced CSF A $\beta 42$ concentrations may be also found in other diseases, without plaques, like bacterial meningitis [32]. Thus, presented theory doesn not explain a selective lowering in the CSF A $\beta 42$ concentration [33]. Other hypothesis includes reduction in the rate of $A \beta 42$ generation [34] or increased degradation of $\mathrm{A} \beta 42$ [35].

The decrease of CSF A $\beta 42$ concentrations in AD patients has been validated in many studies that proved consistent findings concerning a mean fold change of 0.56 for CSF A $\beta 42$ compared to cognitively unimpaired elderly [36]. The study of Hulstaert et al. [37] has estimated that the sensitivity and specificity of the use of $\mathrm{A} \beta 42$ alone to distinguish AD patients from elderly controls were $78 \%$ and $81 \%$, respectively. Consistent findings were evaluated by other authors, who also reported similar sensitivity and specificity (78\% and $83 \%$, respectively) in the differentiation between AD patients and elderly controls [38]. It has been estimated that the CSF A $\beta 42$ measurement is useful in the correct classification of $87 \%$ of the subjects, when non-Alzheimer's dementia patients and non-demented individuals were compared [39]. It is also suggested that decrease of CSF A $\beta 42$ is early indicator of clinically "silent" brain amyloidosis [40].

Despite CSF A $\beta 40$ as alone biomarker is not promising $\mathrm{AD}$ biomarker, there is currently no doubt that the CSF concentration ratio of $A \beta 42 / A \beta 40$ is superior to $A \beta 42$ alone as a diagnostic tool for AD [15]. Several studies have shown its improved diagnostic accuracy compared with $\mathrm{A} \beta 42$ alone, or with other biomarkers [41-44]. The reason might be because A $\beta 42 / 40$ compensates for abnormally high or low total $A \beta$ load in the CSF in individuals, therefore normalizing interindividual variability in CSF A $\beta 42$ levels $[43,45]$.

Studies examining $A \beta 42 / A \beta 40$ values as an informative tool across the spectrum of AD may be categorized into three main groups: (1) diagnostic studies for AD, including those using clinical diagnosis as reference (case-control design), and also including comparison to the amyloid PET as a proxy of $\mathrm{AD}$ pathology; (2) investigations of the differential diagnosis between $\mathrm{AD}$ and other neurodegenerative disorders; (3) prognostic studies, where the A $\beta 42 / \mathrm{A} \beta 40$ ratio was tested for its ability to predict progression from preclinical to the stage of dementia.

Concordance between A $\beta$ PET imaging results and CSF biomarker concentration has been observed with different A $\beta$ PET tracers. In some cases, studies of both $\mathrm{AD}$ patients and cognitively normal individuals showed an inverse, non-linear correlation between $\mathrm{A} \beta 42$ and amyloid PET, but not A $\beta 40$, using the tracer Pittsburgh compound B (PiB) $[29,46]$. Similarly, A $\beta 40$ alone showed significantly lower discriminative power than $\mathrm{A} \beta 42$ alone in identifying ${ }^{18} \mathrm{~F}$-flutemetamol-positive patients [47]. Some recent studies reported lower concentrations of CSF A $\beta 40$ in PiB amyloidpositive individuals compared with a PiB-negative. While high concordance between CSF A $\beta 42$ levels and amyloid- $\beta$ PET imaging is now well established $[48,49]$, discordance between CSF A $\beta 42$ levels and PET imaging-positive results is also a known phenomenon. Obviously, discordant results are more common in cognitively normal individuals [46, 50-52], which might be due to the two measures providing partially independent information [51]. However, the concordance with $\mathrm{PiB}$ imaging status clearly and highly significantly improves from $\sim 75 \%$ for $\mathrm{A} \beta 42$ alone to $~ 90 \%$ for the $\mathrm{A} \beta 42 / \mathrm{A} \beta 40$ ratio $[30,50] ; \mathrm{CSF} \mathrm{A} \beta 42 / \mathrm{A} \beta 40$ and $\mathrm{A} \beta 42 / \mathrm{A} \beta 38$ ratios have also been strongly associated with ${ }^{18} \mathrm{~F}$-flutemetamol PET status [53, 54].

The discordance seen in some investigations comparing $A \beta 42$ in CSF and PET amyloid- $\beta$ imaging leads to a hypothesis that they reflect different aspects of amyloid pathology [51]. Evidence that CSF A $\beta 42$ concentration decreases before amyloid- $\beta$ is detectable with PET imaging suggests that CSF A $\beta 42$ is a more sensitive marker of AD at very early stages, while $A \beta$ PET may be used for better grading of early AD [48]. Additional studies are needed to understand if discordant CSF A $\beta 42$ and PET A $\beta$ imaging could allow further stratification of preclinical AD patients [49]. Palmqvist et al. [55] compared CSF biomarker concentration with PET measurements in patients with MCI-AD rather than AD and found that amyloid PET and CSF biomarkers are able to identify early AD with high accuracy. They found no improvement when combining CSF and PET amyloid measures than using either CSF A $\beta 42$ or tTau alone [55]. Hence, for the moment, the choice between using CSF or A $\beta$ PET biomarkers for identifying early AD could be based on availability of PET scanners, the associated cost, and physician/patient preferences [56].

Biomarkers for $\mathrm{AD}$ such as the $\mathrm{A} \beta$ peptides have been found to have also some utility in helping to differentiate between $\mathrm{AD}$ and other types of neurologic conditions, such as non-AD dementia, which may have similar clinical 
symptoms $[43,57,58]$. A $\beta 40$ levels were found to be lower in cerebral amyloid angiopathy (CAA) and CAA-related inflammation (CAA-I) [59, 60], FTD [61-65], vascular dementia (VaD), and dementia with Lewy bodies (DLB) [53, 58] compared with AD. A $\beta 42$ levels often overlap between $\mathrm{AD}$ and other dementia groups with the exception of much lower levels observed in CAA patients [59]. Therefore, as a stand-alone measure, it is practically useless in differential diagnostics [61]. On the other hand, there is evidence that differences between $\mathrm{AD}$ and non- $\mathrm{AD}$ dementias may be more pronounced using a ratio of CSF $\mathrm{A} \beta 42 / \mathrm{A} \beta 40$ (or $\mathrm{A} \beta 42 /$ $\mathrm{A} \beta 38$ ) than $\mathrm{A} \beta 42$ alone, and could therefore help differentiate $\mathrm{AD}$ from other disorders with similar clinical symptoms $[50,53]$. The $A \beta 42 / A \beta 40$ ratio has shown greater differential diagnostic accuracy compared with A $\beta 42$ alone or other CSF biomarkers [43], with several studies applying $A \beta 42 / A \beta 40$ ratio measures to distinguish $\mathrm{AD}$ from non- $\mathrm{AD}$ dementia [41, 53, 57, 58, 61, 65-71]. Examples of types of dementia in which the $A \beta 42 / A \beta 40$ ratio has improved discrimination from $\mathrm{AD}$ and non-demented controls, compared with $\mathrm{A} \beta 42$ alone, are FTD [58, 61, 67, 72], VaD [58] and DLB [58].

Lewczuk and colleagues [41] demonstrated that the $\mathrm{A} \beta 42 / \mathrm{A} \beta 40$ ratio identified more $\mathrm{AD}$ patients correctly from a population including $\mathrm{AD}$, non-Alzheimer's dementia (nAD) and control subjects compared with $\mathrm{A} \beta 42$ alone (AD vs controls: $94 \%$ vs $87 \%$ patients correctly classified; $A D$ vs nAD plus controls: $91 \%$ vs $87 \%$ ) [41]. The same conclusion was reached in another study from the same group, with entirely different cohorts, and different ELISAs [44]. Spies et al. [58] reported both sensitivity and specificity of $>80 \%$ using the $A \beta 42 / A \beta 40$ ratio to differentiate $A D$ from FTD, $\mathrm{DLB}, \mathrm{VaD}$, and other non-AD neurodegeneration conditions. Together these studies strongly suggest that $\mathrm{A} \beta 42 / \mathrm{A} \beta 40$ ratio may be also of use in differential diagnosis, provided the differential diagnosis question is properly formulated.

A $\beta$ peptides longer than 42 or shorter than 40 amino acid residues have been also tested as potential AD biomarkers. For example, $A \beta 43$ isomer has been reported decreased in $\mathrm{AD}$, with a similar diagnostic accuracy as CSF A $\beta 42$ [73, 74]. The clinical investigations have revealed no difference between CSF A $\beta 38$ levels in AD subjects and control individuals [36], however CSF A $\beta 38$ correlates with PET A $\beta$ [75]. The authors conclude that the ratio of CSF A $\beta 42 / A \beta 38$ is better at predicting $A \beta$-positive PET than CSF $A \beta 42$ alone and comparable to CSF $A \beta 42 / A \beta 40$ ratio [53]. Moreover, CSF A $342 / \mathrm{A} \beta 38$ ratio might be helpful in the differentiation between $\mathrm{AD}$ and dementia with Lewy bodies (DLB) [76] and other non-AD dementias [53].

Since oligomerization of $A \beta$ monomers (mostly those ending at the $\mathrm{C}$-terminal 42 ) seems the very first event on the pathway of the development of $\mathrm{AD}, \mathrm{A} \beta$ oligomers seem to play a role in $A D$ diagnostics. Soluble $A \beta$ oligomers $(A \beta O s)$ are more toxic than non-soluble forms in $A \beta$ plaques [77].
It has been proved that $\mathrm{A} \beta \mathrm{O}$ s isolated from brains of $\mathrm{AD}$ patients may reduce number of synapses and enhanced longterm synaptic depression in regions of brain, that are responsible for memory, what was presented on animal models of AD [78]. Some clinical investigations have revealed a significant increase in CSF A $\beta O$ s in AD patients compared to age-matched controls. In addition, an inverse correlation between $\mathrm{A} \beta \mathrm{O}$ levels and with mini-mental state examination (MMSE) score was observed. Based on area under ROC curve (AUC) of $A \beta O$ s (AUC $=0.860$ with $80 \%$ sensitivity and $88 \%$ specificity), these findings suggest the significance of oligomers in the diagnosis of AD patients [79]. Comparable results were demonstrated by other investigators, who assessed significantly elevated CSF A $\beta O$ s concentrations as well as the $\mathrm{A} \beta \mathrm{O} / \mathrm{A} \beta 42$ ratio in $\mathrm{AD}$ patients in comparison to age-matched control individuals [80]. The study of Fukumoto et al. has indicated that $\mathrm{A} \beta \mathrm{O}$ s might be useful in the discrimination between AD/MCI patients and cognitively normal control, thus elevated $\mathrm{A} \beta \mathrm{O}$ levels may predict the conversion of $\mathrm{MCI}$ to $\mathrm{AD}$ [81]. Moreover, high or measurable CSF A $\beta O$ concentrations correlated with elevated risk of $\mathrm{AD}$ [82]. These investigations suggest that higher levels of oligomeric CSF A $\beta 40$ could be a potential biomarker useful in the diagnosis of $\mathrm{AD}$ with diagnostic sensitivity and specificity greater than $95 \%$ and $90 \%$, respectively [83]. Opposite findings were obtained by other authors, who revealed no significant changes in $\mathrm{A} \beta \mathrm{O}$ s levels in $\mathrm{AD}$ patients [84, 85]. In conclusion, the studies concerning the usefulness of $\mathrm{A} \beta$ oligomers are limited and have been inconsistent due to methodological issues that complicate measurement of $A \beta$ oligomers in CSF, however give hope to improved diagnosis of $\mathrm{AD}$ patients [86].

\section{Tau protein and its phosphorylated forms}

Tau proteins belong to the family of microtubule-associated molecules that are found in neuronal and non-neuronal cells. This protein has six isoforms with the lengths range from 352 to 441 amino acid residues [87, 88]. Tau proteins play a role in neuronal microtubule stability, and may be also involved in promoting microtubule nucleation, growth, and bundling. In addition, the studies performed on animal models have revealed that expression of Tau protein reflects the process of neurofibrillary tangle formation, rather than tangles themselves, and is responsible for synapse and neuronal loss. The total Tau protein concentration was proved to be a nonspecific marker of neuronal destruction in neurodegeneration. A meta-analysis investigation has found that all reported studies indicate increased CSF Tau levels in AD patients [89]. Moreover, increased CSF Tau concentrations might be also found in patients with other neuropsychiatric diseases such as CJD [90]. 
In contrast to Tau protein, being a very sensitive biomarker of neurodegeneration, but unspecific for a particular condition, pTau proteins seem to reflect more specific alterations in Tau metabolism in AD [40]. For example, pTau 181 remains unchanged, whereas total Tau is increased, after acute stroke. Tau-microtubule interactions are regulated by the phosphorylation of Tau molecules [91]. Thus, hyperphosphorylated Tau or oligomeric Tau might be involved in synaptic degeneration, while granular Tau oligomers are responsible for neuronal loss [92]. It is suggested that adding the measurements of soluble oligomers of Tau protein (TauOs) to the panel of CSF biomarkers could improve the diagnosis of AD. The toxicity of TauOs seems to be a potential pathogenic factor acting on the initial stages of this disease and may be responsible for seeding Tau pathology within AD brains [93].

Several other mid-domain phosphorylated tau residues, including threonine 181 (pTau181), threonine 231 (pTau231), serine 235 (pTau235), serine 199 (pTau199) $[94,95]$ as well as for the C-terminal residues serine 396 and 404 [96] have been found. It was proven that CSF levels of pTau181, pTau199 and pTau231 had a similar performance to discriminate $\mathrm{AD}$ from other neurodegenerative disorders and non-demented controls [97]. In addition, the CSF concentrations of pTau181 are significantly increased in $\mathrm{AD}$ patients with clinical diagnoses neurochemically supported by decreased A $\beta 42$ in the CSF [39], which might suggest that pTau181 is not only a marker of simple neuronal loss. Similar results were presented by other authors, who revealed significantly higher levels of CSF pTau 181 in $\mathrm{AD}$ patients when compared to patients with frontotemporal degeneration, DLB, Parkinson's disease (PD) or multiple system atrophy [98, 99]. The study of Parnetti et al. [100] has indicated that pTau181 might be used as a biomarker for distinguishing between AD and DLB. Moreover, phosphorylation of Tau protein at both the threonine 231 and serine 235 positions was proved to be elevated in MCI patients who progress to $\mathrm{AD}$ within the follow-up period [101].

Some authors suggest the role of pTau in the prediction of AD development. Buchhave et al. [102] assessed the ability of CSF pTau to predict development to AD within 9-10 years in MCI patients and compared CSF biomarkers between early and late converters to AD. At baseline, pTau concentrations were significantly higher in patients who converted to $\mathrm{AD}$ during follow-up compared with nonconverters. Moreover, levels of pTau were significantly elevated in early converters in comparison to late converters, while a baseline $\mathrm{A} \beta 42 / \mathrm{p}$-tau ratio predicted the $\mathrm{AD}$ development within 9.2 years with a sensitivity of $88 \%$, specificity of $90 \%$, negative predictive value of $86 \%$ and positive predictive value of $91 \%$. The authors conclude that about $90 \%$ of MCI patients and pathologic CSF biomarker levels at baseline develop AD within 9-10 years [102].

\section{Diagnostic-oriented interpretation of the biomarkers pattern: the Erlangen Score}

The pattern of decreased CSF A $\beta 42$ concentrations and/or A $\beta 42 / 40$ ratio, along with elevated CSF levels of Tau and/ or pTau, as discussed so far, presented two pathophysiologic processes of $\mathrm{AD}$ such as amyloidosis and neurodegeneration. These CSF biomarkers show high diagnostic accuracy, and might be routinely used as an AD diagnostics tool in some countries. However their global acceptance is hampered due to lack of comparability of the results achieved in different laboratories as well as using different analytical methods. This has already been addressed, to some extent, by efforts to standardize procedures for collection of samples, assay calibrators, and measurement protocols, however the global acceptance of these novel approaches will certainly need time [103-105]. In addition, as the AD CSF biomarkers are more often measured in clinical use, interpretation of these results required expertise. The question remains how to interpret the information given by the biomarkers, that is often heterogeneous. Thus, biomarkers in some cases falling into clear-cut normal/abnormal categories. To harmonize the diagnostic-oriented interpretation of the profiles of CSF biomarkers, the Erlangen Score (ES) interpretation algorithm was first proposed [106], followed by other approaches, including logistic regression models [107], classification scales based on the number of pathologic biomarkers, such as the Paris-Lille-Montpellier (PLM) scale [108], or a descriptive, nominal-scale A/T/N system [109].

According to the Erlangen Score, result of CSF with all biomarkers normal is scored with 0 points, and interpreted as "no neurochemical evidence for AD"; a pattern with border zone changes in one biomarkers' group (either $\mathrm{A} \beta$ or Tau/pTau, but not both) results in the score of 1 , and is reported as "neurochemically improbable AD"; a CSF result with evident alterations in either $A \beta$ metabolism (decreased A $\beta 42$ concentration or $A \beta 42 / A \beta 40$ ratio) or tau metabolism (increased Tau levels and/or pTau181) but not both is scored 2 points; the same score is given in the case of border zone alterations in the CSF biomarkers of both groups. A result with evident changes in one biomarkers' group (either $\mathrm{A} \beta$ or Tau) accompanied by border zone alterations in the other group is scored three points; these two cases (with the $\mathrm{ES}=2$ or 3) are interpreted as "neurochemically possible AD". Evident changes in both $\mathrm{A} \beta$ and Tau groups result in four points, and are interpreted as "neurochemically probable AD". Finally, isolated, very high Tau levels is reported as suspected rapidly progressing neurodegeneration with improbable AD. However, the same Tau levels, together with pathologic $A \beta 42$ concentrations/ratio would shift the interpretation to possible or even probable $\mathrm{AD}$ depending 
(if pTau is normal or not, respectively). The Erlangen Score pattern can be summarized and reported to clinicians in a graphical form, that was presented in Fig. 1.

One of the core concepts in the ES algorithm is the border zone result. They need to be, perhaps arbitrary, defined by each laboratory, with suggested value of about $10 \%$. Irrespectively of the magnitude, however, it is important to note that border zones of the ES are asymmetric; they affect exclusively results on the pathologic side of the reference value. For example, with the reference value of $A \beta 42 / 40$ ratio in Erlangen laboratory being 0.05, all results above this cut off are considered entirely normal, but results within $0.045-0.05$ are interpreted as "borderline pathologic". Similarly, results of Tau lower than $320 \mathrm{pg} / \mathrm{ml}$ are considered normal, but results within $320-350 \mathrm{pg} / \mathrm{ml}$ are considered borderline pathologic. Such asymmetric distribution of the interpretation has ethical reasons; in the situation of lacking of effective treatment, we believe it is ethically more correct to underdiagnose patients, by accepting higher ratio of false negative errors than to overdiagnose (by making more false positive errors). Of course, as soon as effective and safe treatment appears on the market, the concept of interpretation of the border zone results will have to be reconsidered.

This concept shows clear advantages compared to other approaches. It enables categorization of the CSF results into five classes on an ordinal scale (0-4), with increasing degree of changes of the CSF biomarkers in AD. Further, it includes, for the first time in the interpretation of the AD biomarkers in CSF, the idea of border zone results. ES improves precise stratification of patients into five categories with increasing degree of the CSF pathology, opposite to a dichotomous approach (CSF normal/pathologic) applied earlier [42]. In addition, ES is less complicate in comparison to regression-based approaches [107]; in every-day laboratory routine it does not require computer-based support at

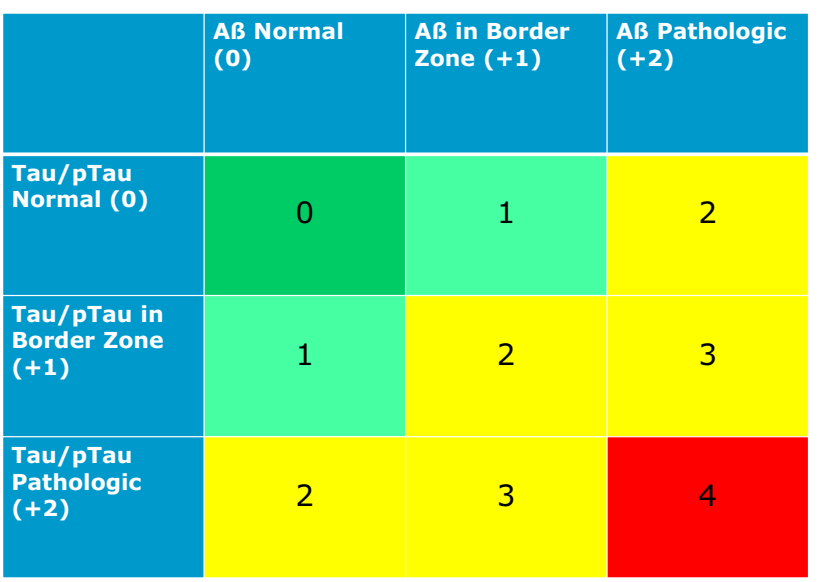

Fig. 1 Erlangen Score interpretation algorithm; adapted from Lewczuk et al. [16] all, although it is easily coded to provide high-throughput laboratories with automated computer-supported lab systems. When we compared the ES to the A/T/N classification [109], this pattern stratifies individuals into classes on an ordinal scale, and not into entirely descriptive categories, that enables at least semi-quantitative correlation of the CSF findings with other metrics, such as odds ratios, progression hazards, or time to progression from MCI to dementia. Further, as an ordinal-scale classification system, the ES provides to take border zone laboratory results into consideration, easily incorporating them into the interpreting algorithm. Finally, ES is more adjustable, enabling inclusion of further potential biomarkers (as long as they reflect amyloid pathology or neurodegeneration at least on an ordinal scale) without necessity to recalculate the ranges (i.e., the number of categories) in comparison to the PLM approach, based on the number of the pathologic CSF biomarkers [108]. Irrespectively of the number of the biomarkers considered, the ES will always classify the CSF patterns into five ordinal categories.

ES has been extensively validated based on cohorts from different expert centers, and on the ground of a broad spectrum of predefined end points. First, ES was proved to correctly classify MCI individuals at increased risk of developing dementia in two independent, large-scale, multicenter cohorts (German Competence Network Dementias, and USADNI), irrespectively of the fact that the two projects used entirely different sample handling protocols, uncorrelated center-specific reference ranges and disparate laboratory analytical platforms [110].

In another study, it turned out that MCI subjects classified as "neurochemically probable AD" presented 8-12 times elevated hazards to develop dementia when compared to those classified as "neurochemically improbable AD", when adjusted for gender, age, MMSE score as well as genotype of APOE. These hazard ratios were clearly time-independent. On contrary, the hazards involved with the cognitive, demographic, and genetic confounders were fully explained by the Erlangen Score [111].

With neuropsychologic and neuroimaging outcome as the end points, it was found that a higher ES predicted a faster disease progression in MCI patients; the subjects with higher ES showed a faster reduction of the whole brain and the hippocampal volumes, as well as faster decrease in MMSE, and a faster increase in ADAS-Cog scores [112].

Finally, Erlangen Score algorithm is enabled to correct prediction of the post-mortem neuropathological outcome on the ground of the intra vitam CSF results of three core AD biomarkers. The probabilities to have AD pathology post mortem in contrast to non-AD pathologies including mainly FTLD, VaD, and LBD increased almost linearly with increasing ES ordered categories, with less than $3 \%$ of the neuropathologically definite $\mathrm{AD}$ patients ( 3 out of 106) were 
categorized as neurochemically improbable $\mathrm{AD}(\mathrm{ES}=0$ or 1) [113].

\section{Novel candidate biomarkers for AD}

A number of CSF biomarkers specific for pathologic changes, as well as those unspecific markers of oxidative damage or inflammation in AD have been tested, but many of them have only been reported in single studies [114]. Several novel potential candidate biomarkers (summarized in Table 1) have been proposed and investigated, however most of them have not been validated and integrated into diagnostic guidelines [30].

Novel fluid biomarkers were grouped, based on the corresponding pathophysiologic $\mathrm{AD}$ mechanism, including $\mathrm{A} \beta$ metabolism (A $338, A \beta O s, B A C E 1)$, vascular dysregulation (heart-type fatty acid-binding protein-hFABP), inflammation and glial activation (triggering receptor expressed on myeloid cells 2-TREM2 and its soluble variant-sTREM2, chitinase-3-like protein $1-$ YKL-40, interferon- $\gamma$-induced protein 10-IP10), synaptic dysfunction (neurogranin, synaptosome-associated protein 25-SNAP-25 and synaptotagmin-1-SYT-1), $\alpha$-Synulcein pathology ( $\alpha$-synuclein), TDP43 pathology (TAR DNA binding protein 43-TDP-43), iron toxity (ferritin) and other neuronal proteins (visinin-like protein 1-VILIP-1 and neurofilament light-NFL) [115-138]. Currently, many other candidates for AD biomarkers are under intensive investigations, including selected metalloproteinases (MMPs) and their tissue inhibitors [136]. For example, CSF concentrations of MMP-9 are significantly lower, while MMP-3 levels are significantly elevated in AD patients in comparison to the elderly individuals without cognitive deficits. In addition, MMP-2, TIMP-1 and TIMP-2 show no significant changes among the groups investigated (AD, MCI patients and elderly individuals without cognitive deficits). Taken together, this might indicate that these proteins play a potential role in the pathophysiology of $\mathrm{AD}$ and diagnostics, however other studies performed on larger group of patients need to be performed to establish their potential diagnostic utility [136].

Although changes in the metabolism of $A \beta$ are currently considered the earliest detectable events in $\mathrm{AD}$, interventional strategies based on the $\mathrm{A} \beta$ hypothesis are still disappointing $[139,140]$. This calls for more extensive researches of other hypotheses, of which those related to Tau seem particularly attractive [141]. This is further supported by the observation that cognitive symptoms in $\mathrm{AD}$ are in direct relation to the biomarkers of neurodegeneration rather than to $A \beta$ deposition biomarkers. In neuropathological

Table 1 Potential significance of novel biomarkers of AD

\begin{tabular}{|c|c|c|c|}
\hline Pathophysiological mechanism & Fluid biomarker & Alterations in $\mathrm{AD}$ & References \\
\hline $\mathrm{A} \beta$ metabolism & $\begin{array}{l}\beta \text {-site amyloid precursor protein cleaving } \\
\text { enzyme } 1 \text { (BACE1) }\end{array}$ & $\begin{array}{l}\text { Increased levels/activity in CSF and increased } \\
\text { activity in plasma }\end{array}$ & [116-118] \\
\hline Vascular dysregulation & Heart-type fatty acid-binding protein (hFABP) & $\begin{array}{l}\text { Consistently increased in CSF, but no change } \\
\text { in plasma or serum }\end{array}$ & {$[119,120]$} \\
\hline \multirow[t]{4}{*}{ Inflammation/glial activation } & $\begin{array}{l}\text { Triggering receptor expressed on myeloid } \\
\text { cells } 2 \text { (TREM2) and its soluble variant } \\
\text { (sTREM2) }\end{array}$ & $\begin{array}{l}\text { Increased in CSF, but no change in plasma } \\
\text { levels }\end{array}$ & {$[121,122]$} \\
\hline & Chitinase-3-like protein 1 (YKL-40) & Increased in CSF and plasma & {$[123,124]$} \\
\hline & Interferon- $\gamma$-induced protein 10 (IP-10) & Inconsistent results in CSF, plasma or serum & [125] \\
\hline & $\begin{array}{l}\text { Matrix metalloproteinase-9 and -3 (MMP-9 } \\
\text { and MMP-3) }\end{array}$ & $\begin{array}{l}\text { Increased in CSF MMP-3 } \\
\text { Decreased in CSF MMP-9 }\end{array}$ & [136] \\
\hline \multirow[t]{3}{*}{ Synaptic dysfunction } & Neurogranin & $\begin{array}{l}\text { Increased in CSF, but no change in plasma; } \\
\text { Increased CSF Neurogranin seems to be } \\
\text { specific for AD }\end{array}$ & {$[126,127]$} \\
\hline & $\begin{array}{l}\text { Synaptosome-associated protein } 25 \\
\text { (SNAP-25) }\end{array}$ & Increased in CSF & [128] \\
\hline & Synaptotagmin-1 (SYT-1) & Increased in CSF & [129] \\
\hline$\alpha$-Synuclein pathology & $\alpha$-Synuclein & Increased in CSF & {$[130,131]$} \\
\hline TDP-43 pathology & TDP-43 & Increased in plasma & [132] \\
\hline Iron metabolism & Ferritin & $\begin{array}{l}\text { Increased in CSF levels is associated with } \\
\text { cognitive decline, no changes in plasma }\end{array}$ & [133] \\
\hline \multirow[t]{2}{*}{ Neuronal proteins } & Visinin-like protein 1 (VILIP-1) & Increased in CSF and plasma & {$[134,135]$} \\
\hline & Neurofilament light (NF-L) & $\begin{array}{l}\text { Consistently increased in CSF and increased } \\
\text { in plasma; May serve as simple, noninvasive } \\
\text { screening tool }\end{array}$ & {$[137,138,159]$} \\
\hline
\end{tabular}


investigations, a clear correlation was indicated between the degree of post-mortem neurofibrillary tangle pathology and a patient's cognitive functions intra vitam [142, 143]. Following this line of argumentation, a novel assay capable to specifically measure non-phosphorylated forms of Tau molecules (Non-P-Tau) was recently developed [144]. Interestingly, it significantly improved the proportion of correctly classified patients (99\%) compared to that achieved by the assays used routinely so far: Tau (90\%), pTau181 (62\%) and $14-3-3$ (91\%) [145]. Furthermore, Non-P-Tau assay is extensively used in differential diagnosis of other dementias, particularly those with profound Tau pathology (like FTLD), although final conclusions have not been reached yet [146].

Another potentially interesting candidate in AD differential diagnosis might be $\alpha$ Synuclein $[131,147]$. A vast majority of studies published so far reports reduced CSF levels of total $\alpha$ Syn in PD subjects, in comparison to both healthy controls and/or patients with other neuropsychiatric disorders [148]. On the other hand, large proportion of papers shows that CSF total $\alpha$ Syn concentrations tend to increase in AD compared to the controls [149]. Increased $\alpha$ Syn concentrations in the AD subjects, along with moderate correlation between $\alpha$ Syn and Tau/pTau181 in the current study reconfirm the data and the conclusions reported by many investigators, that the increased CSF $\alpha$ Syn in AD seems to rather reflect unspecific neurodegeneration and not specific process characteristic for $\mathrm{AD}[150,151]$. Indeed, considering that predominant source of $\alpha$ Syn in the brain is presynaptic neuronal terminals, it seems reasonable to hypothesize that degenerating neurons passively release $\alpha$ Syn molecules, which then diffuse to the CSF at increased rate.

Further investigations are also needed to clarify association between the biomarkers and clinical presentation such as cognitive measures, and the effects of patient variables such as sex, APOEE4 status, comorbidities.

\section{Novel analytical platforms in biomarkers' research}

Development of novel technologies for biomarkers' research and diagnostic applications has faced the most rapid progress in the last decades [152]. Driven by the needs to improve the quality of performance of already established biomarkers, and to enhance analytical sensitivity to search for novel candidates (like those in the blood, for example), new technological platforms have been developed since the first methods to analyze AD biomarkers in the CSF (ELISA and Western blot) were established back in 1990's.

A mass-spectrometry proteomic is often used in search for novel biomarkers. Its advantage relays mostly on the fact that it can directly analyze the molecule in question; the drawback, however, is that mass spectrometry is usually less effective, compared to immunoassays, in the analysis of intacted larger molecules. To overcome this limitation, approaches have been developed that combine advantages of mass spectrometry with ligand-based techniques. As a result, enzyme-linked immuno mass spectrometry assays have been developed [153] that provide improved analytical sensitivity compared to conventional ELISA.

Another issue in $\mathrm{AD}$ biomarker development and their clinical application relates to sample volume limitation. Currently, CSF is regarded as the exclusive source of the fluid-based AD biomarkers (although the first blood-based biomarkers seem appear on the horizon); as a consequence, laboratories need to overcome limitation in availability of the diagnostic and/or human research material. To overcome this issue, multiplexing technologies have been developed that enable simultaneous quantification of several biomolecules in a single, minute sample volume [154, 155]. Advantage of multiplexing is that it analyzes all relevant biomarkers in exactly the same sample and under exactly the same conditions. This is of crucial importance since eventual interpretation of the results derived from the CSF, not only in case of neurodegeneration but even more strongly in neuroinflammation, relays on a pattern of several biomarkers and not on unidimensional result of a single analyte [156]. The drawback of multiplexing, however, is that it is difficult to find such set of antibodies that would be sensitive enough to capture molecules of interest and simultaneously would not cross-react with one another. Similarly, all analytical reactions must take place under the same conditions (dilution buffer, incubation temperature and time), and hence these conditions cannot be optimized for every reaction but must be a compromise across them. Particularly, all the molecules of interest must fit approximately the same range of concentration due to the fact that all of them are, by definition, prediluted to the same degree with the assay buffer [157].

A Single-Molecule Array (Simoa $\left.{ }^{\circledR}\right)$ has been developed by a company Quanterix, as a combination of generation of ELISA-like sandwich complexes which, after formation on magnetic beads are subsequently transferred onto an array of microwells, and sophisticated statistical software capable to interpret the signal in a different manner depending on the number of signal-emitting beads per microwell [158]. Application of this ultrasensitive technology seems to be particularly relevant for low-concentration candidate biomarkers in the blood [159].

Another interesting concept is the application of the polymerase chain reaction (PCR) property to amplify a single DNA copy to many orders of magnitude for development of ultrasensitive AD biomarkers immunoassays. With this technology, molecules are captured between magnetic beads coated with antibodies modified with DNA molecules that are subsequently amplified to generate strong signal [160]. 
To finish this short technology overview, a technology of immuno-magnetic reduction developed by a company $\mathrm{MagQu}$ is perhaps worth mentioning. Briefly, analytes are captured by magnetic nanoparticles coated with specific antibodies, which lead to a concentration-dependent decrease of the oscillations of the nanoparticles in alternating magnetic field. Advantage of this technology relays, among other, on application of only one antibody, in contrast to majority of other platforms, which use two [161].

\section{Conclusion}

$\mathrm{AD}$ is age-related neurodegenerative disease characterized by progressive synaptic damage and neuronal loss. The disease affects a substantial proportion of elderly. The cause of $\mathrm{AD}$ remains still unresolved. The hallmark pathological features of $\mathrm{AD}$ are senile plaques composed of $\mathrm{A} \beta$ and neurofibrillary tangles (NFTs) of Tau protein within patients' brain. Four biomarkers in the CSF (A $\beta 42, \mathrm{~A} \beta 42 / 40$, Tau, and pTau181) have been extensively studied and validated as core AD biomarkers. Fluid biochemical markers measured in CSF hold promise for enabling more effective drug development and establishing a more personalized medicine approach for $\mathrm{AD}$ diagnosis and treatment. Despite large gains in our understanding of AD pathogenesis, validated biomarkers for early detection and accurate diagnosis are sorely needed.

Acknowledgements This invited review was funded by the Polish Ministry of Science and Higher Education under the agreement No. 879/P-DUN/2019. PL received consultation and/or lecture honoraria from IBL International, Fujirebio Europe, AJ Roboscreen, and Roche. MŁZ received lecture honoraria from Roche.

Open Access This article is licensed under a Creative Commons Attribution 4.0 International License, which permits use, sharing, adaptation, distribution and reproduction in any medium or format, as long as you give appropriate credit to the original author(s) and the source, provide a link to the Creative Commons licence, and indicate if changes were made. The images or other third party material in this article are included in the article's Creative Commons licence, unless indicated otherwise in a credit line to the material. If material is not included in the article's Creative Commons licence and your intended use is not permitted by statutory regulation or exceeds the permitted use, you will need to obtain permission directly from the copyright holder. To view a copy of this licence, visit http://creativecommons.org/licenses/by/4.0/.

\section{References}

1. Bain LJ, Jedrziewski K, Morrison-Bogorad M, Albert M, Cotman $\mathrm{C}$, Hendrie $\mathrm{H}$, et al. Healthy brain aging: a meeting report from the Sylvan M. Cohen Annual Retreat of the Pennsylvania Institute on Aging. Alzheimer Dement. 2008;4:443-6.
2. Lane CA, Hardy J, Schott JM. Alzheimer's disease. Eur J Neurol. 2018;25(1):59-70.

3. Alzheimer's Association Report. 2019 Alzheimer's disease facts and figures Alzheimer's Association. Alzheimers Dement. 2019;15(3):321-87.

4. Hort J, O'Brien JT, Gainotti G, Pirttila T, Popescu BO, Rektorova I, et al. EFNS guidelines for the diagnosis and management of Alzheimer's disease. Eur J Neurol. 2010;17(10):1236-48.

5. Thies W, Bleiler L. Alzheimer's disease facts and figures. Alzheimers Dement. 2011;7(2):208-44.

6. Qiu C, von Strauss E, Bäckman L, Winblad B, Fratiglioni L. Twenty-year changes in dementia occurrence suggest decreasing incidence in central Stockholm Sweden. Neurology. 2013;80(20):1888-944.

7. Schrijvers EM, Verhaaren BF, Koudstaal PJ, Hofman A, Ikram MA, Breteler MM. Is dementia incidence declining? Trends in dementia incidence since 1990 in the Rotterdam Study. Neurology. 2012;78(19):1456-63.

8. Rocca WA, Petersen RC, Knopman DS, Hebert LE, Evans DA, Hall KS, et al. Trends in the incidence and prevalence of Alzheimer's disease, dementia, and cognitive impairment in the United States. Alzheimers Dement. 2011;7(1):80-93.

9. Reitz C, Brayne C, Mayeux R. Epidemiology of Alzheimer disease. Nat Rev Neurol. 2011;7(3):137-52.

10. de Leon MJ, Golomb J, George AE, Convit A, Tarshish CY, McRae T, et al. The radiologic prediction of Alzheimer disease: the atrophic hippocampal forma-tion. AJNR Am J Neuroradiol. 1993;14(4):897-906.

11. Blennow K, de Leon MJ, Zetterberg H. Alzheimer's disease. Lancet. 2006;368(9533):387-403.

12. Braak H, Braak E. Frequency of stages of Alzheimerrelated lesions in different age categories. Neurobiol Aging. 1997;18(4):351-7.

13. Dubois B, Feldman HH, Jacova C, Dekosky ST, BarbergerGateau P, Cummings J, et al. Research criteria for the diagnosis of Alzheimer's disease: revising the NINCDS-ADRDA criteria. Lancet Neurol. 2007;6(8):734-46.

14. Petersen RC, Aisen PS, Beckett LA, Donohue MC, Gamst AC, Harvey DJ, et al. Alzheimer's disease neuroimaging initiative (ADNI): clinical characterization. Neurology. 2010;74(3):201-9.

15. Hansson O, Lehmann S, Otto M, Zetterberg H, Lewczuk P. Advantages and disadvantages of the use of the CSF Amyloid $\beta$ (A $\beta$ ) 42/40 ratio in the diagnosis of Alzheimer's Disease. Alzheimers Res Ther. 2019;22(11):34.

16. Lewczuk P, Riederer P, O'Bryant SE, Verbeek MM, Dubois B, Visser PJ, et al. Cerebrospinal fluid and blood biomarkers for neurodegenerative dementias: an update of the Consensus of the Task Force on Biological Markers in Psychiatry of the World Federation of Societies of Biological Psychiatry. World J Biol Psychiatry. 2018;19(4):244-32828.

17. Hampel H, Burger K, Teipel SJ, Bokde AL, Zetterberg H, Blennow K. Core candidate neurochemical and imaging biomarkers of Alzheimer's disease. Alzheimers Dement. 2008;4:38-48.

18. Hansson O, Zetterberg H, Buchhave P, Londos E, Blennow K, Minthon L. Association between CSF biomarkers and incipient Alzheimer's disease in patients with mild cognitive impairment: a follow-up study. Lancet Neurol. 2006;5:228-34.

19. Mattsson N, Zetterberg H, Hansson O, Andreasen N, Parnetti $\mathrm{L}$, Jonsson $\mathrm{M}$, et al. CSF biomarkers and incipient Alzheimer disease in patients with mild cognitive impairment. JAMA. 2009;302:385-93.

20. Braak H, Braak E. Neuropathological staging of Alzheimerrelated changes. Acta Neuropathol (Berl). 1991;82(4):239-59.

21. Guzik-Makaruk EM, Pływaczewski EW, Laskowska K, Filipkowski W, Jurgielewicz-Delegacz E, Mroczko P. A comparative 
analysis of the treatment of decision-making by or for patients with neurodegenerative diseases in four legal jurisdictions. J Alzheimers Dis. 2019;70(1):1-10.

22. Guzik-Makaruk EM, Pływaczewski EW, Mroczko P, OlesiukOkomska M, Kulczyńska-Przybik A. Consent to medical procedures of patients with neurodegenerative diseases: a comparative study of legal regulations in selected European countries and in the United States. J Alzheimers Dis. 2018;63(1):53-67.

23. Kang J, Lemaire HG, Unterbeck A, Salbaum JM, Masters CL, Grzeschik KH, et al. The precursor of Alzheimer's disease amyloid A4 protein resembles a cellsurface receptor. Nature. 1987;325(6106):733-6.

24. Carroll CM, Li YM. Physiological and pathological roles of the $\gamma$-secretase complex. Brain Res Bull. 2016;126:199-206.

25. Portelius E, Price E, Brinkmalm G, Stiteler M, Olsson M, Persson R, et al. A novel pathway for amyloid precursor protein processing. Neurobiol Aging. 2011;32:1090-8.

26. Wiltfang J, Esselmann H, Bibl M, Smirnov A, Otto M, Paul S, et al. Highly conserved and disease-specific patterns of carboxyterminally truncated abeta peptides $1-37 / 38 / 39$ in addition to $1-40 / 42$ in Alzheimer's disease and in patients with chronic neuroinflammation. J Neurochem. 2002;81:481-96.

27. Iwatsubo T, Odaka A, Suzuki N, Mizusawa H, Nukina N, Ihara Y. Visualization of $A \beta 42(43)$ and $A \beta 40$ in senile plaques with end-specific A $\beta$ monoclonals: evidence that an initially deposited species is A $\beta 42(43)$. Neuron. 1994;13:45-53.

28. Lewczuk P, Esselmann H, Meyer M, Wollscheid V, Neumann M, Otto M, et al. The amyloid-beta (abeta) peptide pattern in cerebrospinal fluid in Alzheimer's disease: evidence of a novel carboxyterminally elongated abeta peptide. Rapid Commun Mass Spectrom. 2003;17:1291-6.

29. Fagan AM, Mintun MA, Mach RH, Lee SY, Dence CS, Shah $A R$, et al. Inverse relation between in vivo amyloid imaging load and cerebrospinal fluid A $\beta 42$ in humans. Ann Neurol. 2006;59:512-9.

30. Lewczuk P, Matzen A, Blennow K, Parnetti L, Molinuevo JL, Eusebi P, et al. Cerebrospinal fluid Abeta42/40 corresponds better than Abeta42 to amyloid PET in alzheimer's disease. J Alzheimers Dis. 2017;55:813-22.

31. Begcevic I, Brinc D, Brown M, Martinez-Morillo E, Goldhardt $\mathrm{O}$, Grimmer T, et al. Brain-related proteins as potential CSF biomarkers of Alzheimer's disease: a targeted mass spectrometry approach. J Proteom. 2018;182:12-20.

32. Sjogren M, Gisslen M, Vanmechelen E, Blennow K. Low cerebrospinal fluid b-amyloid 42 in patients with acute bacterial meningitis and normalization after treatment. Neurosci Lett. 2001;314(1/2):33-6.

33. Berge G, Sando SB, Albrektsen G, Lauridsen C, Mřller I, Grřntvedt GR, et al. Alpha-synuclein measured in cerebrospinal fluid from patients with Alzheimer's disease, mild cognitive impairment, or healthy controls: a 2 year follow-up study. BMC Neurol. 2016;16:180.

34. Spies PE, Verbeek MM, van Groen T, Claassen JA. Reviewing reasons for the decreased CSF Abeta42 concentration in Alzheimer disease. Front Biosci (Landmark Ed). 2012;17:2024-34.

35. Itoh $\mathrm{N}$, Arai $\mathrm{H}$, Urakami $\mathrm{K}$, Ishiguro $\mathrm{K}$, Ohno $\mathrm{H}$, Hampel $\mathrm{H}$, et al. Large-scale, multicenter study of cerebrospinal fluid tau protein phosphorylated at serine 199 for the antemortem diagnosis of Alzheimer's disease. Ann Neurol. 2001;50(2):150-6.

36. Olsson B, Lautner R, Andreasson U, Öhrfelt A, Portelius E, Bjerke M, et al. CSF and blood biomarkers for the diagnosis of Alzheimer's disease: a systematic review and meta-analysis. Lancet Neurol. 2016;15:673-84.

37. Hulstaert F, Blennow K, Ivanoiu A, Schoonderwaldt HC, Riemenschneider M, De Deyn PP, et al. Improved discrimination of AD patients using $\beta$-amyloid (1-42) and tau levels in CSF. Neurology. 1999;52(8):1555-622.

38. Galasko D, Chang L, Motter R, Clark CM, Kaye J, Knopman D, et al. High cerebrospinal fluid tau and low amyloid $\beta 42$ levels in the clinical diagnosis of Alzheimer disease and relation to apolipoprotein E genotype. Arch Neurol. 1998;55(7):937-45.

39. Lewczuk P, Esselmann H, Bibl M, Beck G, Maler JM, Otto $\mathrm{M}$, et al. Tau protein phosphorylated at threonine 181 in CSF as a neurochemical biomarker in Alzheimer's disease: original data and review of the literature. J Mol Neurosci. 2004;23(1/2):115-22.

40. Blennow K, Zetterberg H. Biomarkers for Alzheimer's disease: current status and prospects for the future. J Intern Med. 2018;284(6):643-63.

41. Lewczuk P, Esselmann H, Otto M, Maler JM, Henkel AW, Henkel MK, et al. Neurochemical diagnosis of alzheimer's dementia by CSF Abeta42, Abeta42/Abeta40 ratio and total tau. Neurobiol Aging. 2004;25:273-81.

42. Hansson O, Zetterberg H, Buchhave P, Andreasson U, Londos E, Minthon L, et al. Prediction of Alzheimer's disease using the CSF Abeta42/Abeta40 ratio in patients with mild cognitive impairment. Dement Geriatr Cogn Disord. 2007;23:316-20.

43. Engelborghs S. Clinical indications for analysis of Alzheimer's disease CSF biomarkers. Rev Neurol (Paris). 2013;169:709-14.

44. Lewczuk P, Lelental N, Spitzer P, Maler JM, Kornhuber J. Amyloid-beta $42 / 40$ cerebrospinal fluid concentration ratio in the diagnostics of Alzheimer's disease: validation of two novel assays. J Alzheimers Dis. 2015;43:183-91.

45. Wiltfang J, Esselmann H, Bibl M, Hull M, Hampel H, Kessler $\mathrm{H}$, et al. Amyloid beta peptide ratio $42 / 40$ but not A beta 42 correlates with phospho-tau in patients with low- and high-CSF A beta 40 load. J Neurochem. 2007;101:1053-9.

46. Fagan AM, Mintun MA, Shah AR, Aldea P, Roe CM, Mach RH, et al. Cerebrospinal fluid tau and ptau (181) increase with cortical amyloid deposition in cognitively normal individuals: Implications for future clinical trials of Alzheimer's disease. EMBO Mol Med. 2009;1:371-80.

47. Adamczuk K, Schaeverbeke J, Vanderstichele HM, Lilja J, Nelissen N, Van Laere K, et al. Diagnostic value of cerebrospinal fluid abeta ratios in preclinical Alzheimer's disease. Alzheimers Res Ther. 2015;7:75.

48. Palmqvist S, Zetterberg H, Blennow K, Vestberg S, Andreasson U, Brooks DJ, et al. Accuracy of brain amyloid detection in clinical practice using cerebrospinal fluid beta-amyloid 42: a crossvalidation study against amyloid positron emission tomography. JAMA Neurol. 2014;71:1282-9.

49. Blennow K, Dubois B, Fagan AM, Lewczuk P, de Leon MJ, Hampel H. Clinical utility of cerebrospinal fluid biomarkers in the diagnosis of early Alzheimer's disease. Alzheimer's Dement. 2015;11:58-69.

50. Leuzy A, Chiotis K, Hasselbalch SG, Rinne JO, de Mendonca A, Otto M, et al. Pittsburgh compound B imaging and cerebrospinal fluid amyloid-beta in a multicentre european memory clinic study. Brain. 2016;139:2540-53.

51. Mattsson N, Insel PS, Donohue M, Landau S, Jagust WJ, Shaw LM, et al. Independent information from cerebrospinal fluid amyloid-beta and florbetapir imaging in Alzheimer's disease. Brain. 2015;138:772-83.

52. Zwan M, van Harten A, Ossenkoppele R, Bouwman F, Teunissen C, Adriaanse S, et al. Concordance between cerebrospinal fluid biomarkers and [11C] PIB PET in a memory clinic cohort. J Alzheimer's Dis. 2014;41:801-7.

53. Janelidze S, Zetterberg H, Mattsson N, Palmqvist S, Vanderstichele H, Lindberg O, et al. CSF Abeta42/Abeta40 and Abeta42/Abeta38 ratios: better diagnostic markers of Alzheimer disease. Ann Clin Transl Neurol. 2016;3:154-65. 
54. Pannee J, Portelius E, Minthon L, Gobom J, Andreasson U, Zetterberg $\mathrm{H}$, et al. Reference measurement procedure for CSF amyloid beta (abeta)1-42 and the CSF Abeta1-42 /Abeta1-40 ratio- a cross-validation study against amyloid PET. J Neurochem. 2016;139:651-8.

55. Palmqvist S, Zetterberg H, Mattsson N, Johansson P, Alzheimer's Disease Neuroimaging Initiative, Minthon L, et al. Detailed comparison of amyloid PET and CSF biomarkers for identifying early Alzheimer disease. Neurology. 2015;85:1240-9.

56. Palmqvist S, Mattsson N, Hansson O. Alzheimer's disease neuroimaging initiative. Cerebrospinal fluid analysis detects cerebral amyloid-beta accumulation earlier than positron emission tomography. Brain. 2016;139:1226-36.

57. Slaets S, Le Bastard N, Martin J, Sleegers K, Van Broeckhoven C, De Deyn PP, et al. Cerebrospinal fluid A $\beta 1-40$ improves differential dementia diagnosis in patients with intermediate P-tau181P levels. J Alzheimer's Dis. 2013;36:759-67.

58. Spies PE, Slats D, Sjogren JM, Kremer BP, Verhey FR, Rikkert MG, et al. The cerebrospinal fluid amyloid beta42/40 ratio in the differentiation of Alzheimer's disease from non-Alzheimer's dementia. Curr Alzheimer Res. 2010;7:470-6.

59. Verbeek MM, Kremer BP, Rikkert MO, Van Domburg PH, Skehan ME, Greenberg SM. Cerebrospinal fluid amyloid beta (40) is decreased in cerebral amyloid angiopathy. Ann Neurol. 2009;66:245-9.

60. Renard D, Wacongne A, Ayrignac X, Charif M, Fourcade G, Azakri S, et al. Cerebrospinal fluid Alzheimer's disease biomarkers in cerebral amyloid angiopathy-related inflammation. J Alzheimer's Dis. 2016;50:759-64.

61. Bibl M, Mollenhauer B, Lewczuk P, Esselmann H, Wolf S, Otto $\mathrm{M}$, et al. Cerebrospinal fluid tau, p-tau 181 and amyloidbeta38/40/42 in frontotemporal dementias and primary progressive aphasias. Dement Geriatr Cogn Disord. 2011;31:37-44.

62. Pijnenburg YA, Schoonenboom SN, Mehta PD, Mehta SP, Mulder C, Veerhuis R, et al. Decreased cerebrospinal fluid amyloid beta (1-40) levels in frontotemporal lobar degeneration. J Neurol Neurosurg Psychiatry. 2007;78:735-7.

63. Gabelle A, Roche S, Geny C, Bennys K, Labauge P, Tholance Y, et al. Correlations between soluble alpha/beta forms of amyloid precursor protein and Abeta 38, 40, and 42 in human cerebrospinal fluid. Brain Res. 2010;1357:175-83.

64. Gabelle A, Roche S, Geny C, Bennys K, Labauge P, Tholance Y, et al. Decreased sAbetaPPbeta, Abeta38, and Abeta40 cerebrospinal fluid levels in frontotemporal dementia. J Alzheimer's Dis. 2011;26:553-63.

65. Verwey NA, Kester MI, van der Flier WM, Veerhuis R, Berkhof $\mathrm{H}$, Twaalfhoven $\mathrm{H}$, et al. Additional value of CSF amyloid-beta 40 levels in the differentiation between FTLD and control subjects. J Alzheimer's Dis. 2010;20:445-52.

66. Sauvee M, DidierLaurent G, Latarche C, Escanye MC, Olivier JL, Malaplate-Armand C. Additional use of abeta42/abeta40 ratio with cerebrospinal fluid biomarkers P-tau and abeta42 increases the level of evidence of Alzheimer's disease pathophysiological process in routine practice. J Alzheimer's Dis. 2014;41:377-86.

67. Struyfs H, Van Broeck B, Timmers M, Fransen E, Sleegers K, Van Broeckhoven C, et al. Diagnostic accuracy of cerebrospinal fluid amyloid-beta isoforms for early and differential dementia diagnosis. J Alzheimer's Dis. 2015;45:813-22.

68. Welge V, Fiege O, Lewczuk P, Mollenhauer B, Esselmann H, Klafki HW, et al. Combined CSF tau, p-tau181 and amyloid-beta 38/40/42 for diagnosing Alzheimer's disease. J Neural Transm (Vienna). 2009;116:203-12.

69. Tabaraud F, Leman JP, Milor AM, Roussie JM, Barriare G, Tartary M, et al. Alzheimer CSF biomarkers in routine clinical setting. Acta Neurol Scand. 2012;125:416-23.
70. Nutu M, Zetterberg H, Londos E, Minthon L, Nagga K, Blennow $\mathrm{K}$, et al. Evaluation of the cerebrospinal fluid amyloid-beta1-42/ amyloid-beta1-40 ratio measured by alpha-LISA to distinguish Alzheimer's disease from other dementia disorders. Dement Geriatr Cogn Disord. 2013;36:99-110.

71. Paterson RW, Toombs J, Slattery CF, Nicholas JM, Andreasson U, Magdalinou NK, et al. Dissecting IWG-2 typical and atypical Alzheimer's disease: insights from cerebrospinal fluid analysis. J Neurol. 2015;262:2722-30.

72. Baldeiras I, Santana I, Leitao MJ, Ribeiro MH, Pascoal R, Duro $\mathrm{D}$, et al. Cerebrospinal fluid Abeta40 is similarly reduced in patients with frontotemporal lobar degeneration and Alzheimer's disease. J Neurol Sci. 2015;358:308-16.

73. Bruggink KA, Kuiperij HB, Claassen JA, Verbeek MM. The diagnostic value of CSF amyloid-beta43 in differentiation of dementia syndromes. Curr Alzheimer Res. 2013;10:1034-40.

74. Henjum K, Almdahl IS, Ĺrskog V, Minthon L, Hansson O, Fladby T, et al. Cerebrospinal fluid soluble TREM2 in aging and Alzheimer's disease. Alzheimer's Res Ther. 2016;8:17.

75. Mattsson N, Insel PS, Palmqvist S, Stomrud E, van Westen D, Minthon L, et al. Increased amyloidogenic APP processing in APOE $\varepsilon 4$-negative individuals with cerebral $\beta$-amyloidosis. Nat Commun. 2016;7:10918.

76. Mulugeta E, Londos E, Ballard C, Alves G, Zetterberg H, Blennow $\mathrm{K}$, et al. CSF amyloid $\beta 38$ as a novel diagnostic marker for dementia with Lewy bodies. J Neurol Neurosurg Psychiatry. 2011;82:160-4.

77. Lista S, Toschi N, Baldacci F, Zetterberg H, Blennow K, Kilimann I, et al. Cerebrospinal fluid neurogranin as a biomarker of neurodegenerative diseases: a cross-sectional study. J Alzheimer's Dis. 2017;59:1327-34.

78. Shankar GM, Li S, Mehta TH, Garcia-Munoz A, Shepardson NE, Smith I, et al. Amyloid-beta protein dimers isolated directly from Alzheimer's brains impair synaptic plasticity and memory. Nat Med. 2008;14:837-42.

79. Savage MJ, Kalinina J, Wolfe A, Tugusheva K, Korn R, CashMason T, et al. A sensitive abeta oligomer assay discriminates Alzheimer's and aged control cerebrospinal fluid. J Neurosci. 2008;34:2884-977.

80. Herskovits AZ, Locascio JJ, Peskind ER, Li G, Hyman BT. A Luminex assay detects amyloid beta oligomers in Alzheimer's disease cerebrospinal fluid. PLoS ONE. 2013;8:e67898.

81. Fukumoto H, Tokuda T, Kasai T, Ishigami N, Hidaka H, Kondo $\mathrm{M}$, et al. High-molecular-weight beta-amyloid oligomers are elevated in cerebrospinal fluid of Alzheimer patients. FASEB J. 2010;24:2716-26.

82. Hölttä M, Hansson O, Andreasson U. Evaluating amyloid- $\beta$ oligomers in cerebrospinal fluid as a biomarker for Alzheimer's disease. PLoS ONE. 2013;8:e66381.

83. Gao CM, Yam AY, Wang X, Magdangal E, Salisbury C, Peretz D, et al. A $\beta 40$ oligomers identified as a potential biomarker for the diagnosis of Alzheimer's disease. PLoS ONE. 2010;5:e15725.

84. Santos AN, Ewers M, Minthon L, Simm A, Silber RE, Blennow $\mathrm{K}$, et al. Amyloid- $\beta$ oligomers in cerebrospinal fluid are associated with cognitive decline in patients with Alzheimer's disease. J Alzheimer's Dis. 2012;29:171-6.

85. Jongbloed W, Bruggink KA, Kester MI, et al. Amyloid- $\beta$ oligomers relate to cognitive decline in Alzheimer's disease. J Alzheimer's Dis. 2015;45:35-433. https://doi.org/10.3233/JAD-14213 6.

86. Schuster J, Funke SA. Methods for the specific detection and quantitation of amyloid- $\beta$ oligomers in cerebrospinal fluid. J Alzheimer's Dis. 2016;53:53-67. 
87. Mandelkow E, Von Bergen M, Biernat J. Structural principles of tau and the paired helical filaments of Alzheimer's disease. Brain Pathol. 2007;17(1):83-90.

88. Buée L, Bussière T, Buée-Scherrer V, Delacourte A, Hof PR. Tau protein isoforms, phosphorylation and role in neurodegenerative disorders. Brain Res Brain Res Rev. 2000;33(1):95-130.

89. Sunderland T, Linker G, Mirza N, Putnam KT, Friedman DL, Kimmel LH, et al. Decreased $\beta$-amyloid1-42 and increased tau levels in cerebrospinal fluid of patients with Alzheimer disease. JAMA. 2003;289(16):2094-103.

90. Skillback T, Rosen C, Asztely F, Mattsson N, Blennow K, Zetterberg H. Diagnostic performance of cerebrospinal fluid total Tau and phosphorylated Tau in Creutzfeldt-Jakob disease: results from the swedish mortality registry. JAMA Neurol. 2014;71:476-83.

91. Shahani N, Brandt R. Functions and malfunctions of the tau proteins. Cell Mol Life Sci. 2002;59(10):1668-800.

92. Takashima A. Tauopathies and tau oligomers. J Alzheimer's Dis. 2013;37(3):565-8.

93. DeVos SL, Corjuc BT, Oakley DH, Nobuhara CK, Bannon RN, Chase A, et al. Synaptic tau seeding precedes tau pathology in human Alzheimer's disease brain. Front Neurosci. 2018;24(12):267.

94. Ishiguro K, Ohno H, Arai H, Yamaguchi H, Urakami K, Park $\mathrm{JM}$, et al. Phosphorylated tau in human cerebrospinal fluid is a diagnostic marker for Alzheimer's disease. Neurosci Lett. 1999;270:91-4.

95. Kohnken R, Buerger K, Zinkowski R, Miller C, Kerkman D, DeBernardis J, et al. Detection of tau phosphorylated at threonine 231 in cerebrospinal fluid of Alzheimer's disease patients. Neurosci Lett. 2000;287:187-90.

96. Hu YY, He SS, Wang X, Duan QH, Grundke-Iqbal I, Iqbal K, et al. Levels of nonphosphorylated and phosphorylated tau in cerebrospinal fluid of Alzheimer's disease patients: an ultrasensitive bienzyme-substrate recycle enzyme-linked immunosorbent assay. Am J Pathol. 2002;160:1269-78.

97. Hampel H, Buerger K, Zinkowski R, Teipel SJ, Goernitz A, Andreasen N, et al. Measurement of phosphorylated tau epitopes in the differential diagnosis of Alzheimer disease: a comparative cerebrospinal fluid study. Arch Gen Psychiatry. 2004;61:95-102.

98. Vanmechelen E, Van Kerschaver E, Blennow K, et al. CSF Phospho-tau (181P) as a promising marker for discriminating Alzheimer's disease from dementia with Lewy bodies in Alzheimer's disease. Chichester: JohnWiley and Sons; 2001.

99. Blennow K, Vanmechelen E, Hampel H. CSF total tau, A $\beta 42$ and phosphorylated tau protein as biomarkers for Alzheimer's disease. Mol Neurobiol. 2001;24(1-3):87-97.

100. Parnetti L, Lanari A, Amici S, Gallai V, Vanmechelen E, Hulstaert F. CSF phosphorylated tau is a possible marker for discriminating Alzheimer's disease from dementia with Lewy bodies. Neurol Sci. 2001;22(1):77-8.

101. Arai $\mathrm{H}$, Ishiguro $\mathrm{K}$, Ohno $\mathrm{H}$, Moriyama M, Itoh N, Okamura N, et al. CSF phosphorylated tau protein and mild cognitive impairment: a prospective study. Exp Neurology. 2000;166(1):201-3.

102. Buchhave P, Minthon L, Zetterberg H, Wallin AK, Blennow K, Hansson O. Cerebrospinal fluid levels of $\beta$-amyloid 1-42, but not of tau, are fully changed already $5-10$ years before the onset of Alzheimer dementia. Arch Gen Psychiatry. 2012;69(1):98-106.

103. Engelborghs S, Niemantsverdriet E, Struyfs H, Blennow K, Brouns R, Comabella M, et al. Consensus guidelines for lumbar puncture in patients with neurological diseases. Alzheimer's Dement (Amst). 2017;8:111-6.

104. Hansson O, Mikulskis A, Fagan AM, Teunissen C, Zetterberg H, Vanderstichele $\mathrm{H}$, et al. The impact of preanalytical variables on measuring cerebrospinal fluid biomarkers for Alzheimer's disease diagnosis: a review. Alzheimer's Dement. 2018;14(10):1313-23.
105. Bjerke M, Andreasson U, Kuhlmann J, Portelius E, Pannee J, Lewczuk P, et al. Assessing the commutability of reference material formats for the harmonization of amyloid-beta measurements. Clin Chem Lab Med. 2016;54:1177-91.

106. Lewczuk P, Zimmermann R, Wiltfang J, Kornhuber J. Neurochemical dementia diagnostics: a simple algorithm for interpretation of the CSF biomarkers. J Neural Transm. 2009;116:1163-7.

107. Spies PE, Claassen JA, Peer PG, Blankenstein MA, Teunissen $\mathrm{CE}$, Scheltens $\mathrm{P}$, et al. A prediction model to calculate probability of Alzheimer's disease using cerebrospinal fluid biomarkers. Alzheimer's Dement. 2013;9:262-8.

108. Lehmann S, Delaby C, Boursier G, Catteau C, Ginestet N, Tiers $\mathrm{L}$, et al. Relevance of abeta42/40 ratio for detection of alzheimer disease pathology in clinical routine: The PLMR Scale. Front Aging Neurosci. 2018;10:138.

109. Jack CR Jr, Bennett DA, Blennow K, Carrillo MC, Feldman $\mathrm{HH}$, Frisoni GB, et al. A/T/N: An unbiased descriptive classification scheme for Alzheimer disease biomarkers. Neurology. 2016;87:539-47.

110. Lewczuk P, Kornhuber J, German Dementia Competence Network, Toledo JB. US-ADNI: validation of the Erlangen Score algorithm for the prediction of the development of dementia due to Alzheimer's disease in pre-dementia subjects. J Alzheimer's Dis. 2015;48(2):433-41.

111. Baldeiras I, Santana I, Leitao MJ, Vieira D, Duro D, Mroczko $\mathrm{B}$, et al. Erlangen Score as a tool to predict progression from mild cognitive impairment to dementia in Alzheimer's disease. Alzheimer's Res Ther. 2019;11(1):2.

112. Skillbäck T, Kornhuber J, Blennow K, Zetterberg H, Lewczuk P. Alzheimer's disease neuroimaging initiative: Erlangen Score predicts cognitive and neuroimaging progression in mild cognitive impairment stage of Alzheimer's disease. J Alzheimer's Dis. 2019;69(2):551-9.

113. Somers C, Lewczuk P, Sieben A, Van Broeckhoven C, De Deyn PP, Kornhuber J, et al. Validation of the Erlangen Score algorithm for differential dementia diagnosis in autopsy-confirmed subjects. J Alzheimer's Dis. 2019;68(3):1151-9.

114. Blennow K, Zetterberg H. Understanding biomarkers of neurodegeneration: ultrasensitive detection techniques pave the way for mechanistic understanding. Nat Med. 2015;21:217-9.

115. Molinuevo JL, Ayton S, Batrla R, Bednar MM, Bittner T, Cummings J, et al. Current state of Alzheimer's fluid biomarkers. Acta Neuropathol. 2018;136(6):821-53.

116. Mulder SD, van der Flier WM, Verheijen JH, Mulder C, Scheltens $\mathrm{P}$, Blankenstein MA, et al. BACE1 activity in cerebrospinal fluid and its relation to markers of AD pathology. J Alzheimer's Dis. 2010;20:253-60.

117. Shen Y, Wang H, Sun Q, Yao H, Keegan AP, Mullan M, et al. Increased plasma beta-secretase 1 may predict conversion to Alzheimer's disease dementia in individuals with mild cognitive impairment. Biol Psychiatr. 2018;83(5):447-55.

118. Leung YY, Toledo JB, Nefedov A, Polikar R, Raghavan N, Xie $\mathrm{SX}$, et al. Identifying amyloid pathology-related cerebrospinal fluid biomarkers for Alzheimer's disease in a multicohort study. Alzheimer's Dement (Amst). 2015;1:339-48.

119. Guo LH, Alexopoulos P, Perneczky R. Heart-type fatty acid binding protein and vascular endothelial growth factor: cerebrospinal fluid biomarker candidates for Alzheimer's disease. Eur Arch Psychiatry Clin Neurosci. 2013;263:553-60.

120. Mollenhauer B, Steinacker P, Bahn E, Bibl M, Brechlin P, Schlossmacher MG, et al. Serum heart-type fatty acidbinding protein and cerebrospinal fluid tau: marker candidates for dementia with Lewy bodies. Neurodegener Dis. 2007;4:366-75.

121. Heslegrave A, Heywood W, Paterson R, Magdalinou N, Svensson J, Johansson P, et al. Increased cerebrospinal fluid soluble 
TREM2 concentration in Alzheimer's disease. Mol Neurodegener. 2016;11:3.

122. Piccio L, Deming Y, Del-Águila JL, Ghezzi L, Holtzman DM, Fagan AM, et al. Cerebrospinal fluid soluble TREM2 is higher in Alzheimer disease and associated with mutation status. Acta Neuropathol. 2016;131:925-33.

123. Baldacci F, Lista S, Cavedo E, Bonuccelli U, Hampel H. Diagnostic function of the neuroinflammatory biomarker YKL-40 in Alzheimer's disease and other neurodegenerative diseases. Expert Rev Proteom. 2017;14:285-99.

124. Muszyński P, Kulczyńska-Przybik A, Borawska R, LitmanZawadzka A, Słowik A, Klimkowicz-Mrowiec A, et al. The relationship between markers of inflammation and degeneration in the central nervous system and the blood-brain barrier impairment in Alzheimer's disease. J Alzheimer's Dis. 2017;59(3):903-12.

125. Iturria-Medina Y, Sotero RC, Toussaint PJ, Mateos-Pérez JM, Evans AC, Alzheimer's Disease Neuroimaging Initiative. Early role of vascular dysregulation on late-onset Alzheimer's disease based on multifactorial data-driven analysis. Nat Commun. 2016;7:11934.

126. Pereira JB, Westman E, Hansson O, Alzheimer's Disease Neuroimaging Initiative. Association between cerebrospinal fluid and plasma neurodegeneration biomarkers with brain atrophy in Alzheimer's disease. Neurobiol Aging. 2017;58:14-29.

127. Thorsell A, Bjerke M, Gobom J, Brunhage E, Vanmechelen E, Andreasen N, et al. Neurogranin in cerebrospinal fluid as a marker of synaptic degeneration in Alzheimer's disease. Brain Res. 2010;1362:13-22.

128. Brinkmalm A, Brinkmalm G, Honer WG, Frölich L, Hausner L, Minthon L, et al. SNAP-25 is a promising novel cerebrospinal fluid biomarker for synapse negeneration in Alzheimer's disease. Mol Neurodegener. 2014;9:53.

129. Öhrfelt A, Brinkmalm A, Dumurgier J, Brinkmalm G, Hansson $\mathrm{O}$, Zetterberg $\mathrm{H}$, et al. The pre-synaptic vesicle protein synaptotagmin is a novel biomarker for Alzheimer's disease. Alzheimer's Res Ther. 2016;8:41.

130. Mollenhauer B, Cullen V, Kahn I, Krastins B, Outeiro TF, Pepivani I, et al. Direct quantification of CSF $\alpha$-synuclein by ELISA and first cross-sectional study in patients with neurodegeneration. Exp Neurol. 2008;213:315-25.

131. Chiasserini D, Biscetti L, Eusebi P, Salvadori N, Frattini G, Simoni S, et al. Differential role of CSF fatty acid binding protein 3, $\alpha$-synuclein, and Alzheimer's disease core biomarkers in Lewy body disorders and Alzheimer's dementia. Alzheimer's Res Ther. 2017;9:52.

132. Feneberg E, Steinacker P, Lehnert S, Schneider A, Walther P, Thal DR, et al. Limited role of free TDP-43 as a diagnostic tool in neurodegenerative diseases. Amyotroph Lateral Scler Frontotemporal Degener. 2014;15:351-6.

133. Ayton S, Faux NG, Bush AI, Alzheimer's Disease Neuroimaging Initiative. Ferritin levels in the cerebrospinal fluid predict Alzheimer's disease outcomes and are regulated by APOE. Nat Commun. 2015;6:6760.

134. Mroczko B, Groblewska M, Zboch M, Muszyński P, Zajkowska A, Borawska R, et al. MME valuation of visinin-like protein 1 concentrations in the cerebrospinal fluid of patients with mild cognitive impairment as a dynamic biomarker of Alzheimer's disease. J Alzheimer's Dis. 2015;43(3):1031-7.

135. Zetterberg H, Skillbäck T, Mattsson N, Trojanowski JQ, Portelius E, Shaw LM, et al. Association of cerebrospinal fluid neurofilament light concentration with Alzheimer disease progression. JAMA Neurol. 2016;73:60-7.

136. Mroczko B, Groblewska M, Zboch M, Kulczyńska A, Koper OM, Szmitkowski M, Kornhuber J, Lewczuk P, et al. Concentrations of matrix metalloproteinases and their tissue inhibitors in the cerebrospinal fluid of patients with Alzheimer's disease. J Alzheimer's Dis. 2014;40(2):351-7.

137. Rohrer JD, Woollacott IO, Dick KM, Brotherhood E, Gordon E, Fellows A, et al. Serum neurofilament light chain protein is a measure of disease intensity in frontotemporal dementia. Neurology. 2016;87:1329-36.

138. Rojas JC, Karydas A, Bang J, Tsai RM, Blennow K, Liman V, et al. Plasma neurofilament light chain predicts progression in progressive supranuclear palsy. Ann Clin Transl Neurol. 2016;3:216-25.

139. Barage SH, Sonawane KD. Amyloid cascade hypothesis: Pathogenesis and therapeutic strategies in Alzheimer's disease. Neuropeptides. 2015;52:1-18.

140. Morris GP, Clark IA, Vissel B. Inconsistencies and controversies surrounding the amyloid hypothesis of Alzheimer's disease. Acta Neuropathol Commun. 2014;2:135.

141. Pedersen JT, Sigurdsson EM. Tau immunotherapy for Alzheimer's disease. Trends Mol Med. 2015;21:394-402.

142. Braak H, Braak E. Evolution of the neuropathology of Alzheimer's disease. Acta Neurol Scand Suppl. 1996;165:3-12.

143. Holzer M, Holzapfel HP, Zedlick D, Bruckner MK, Arendt T. Abnormally phosphorylated tau protein in Alzheimer's disease: heterogeneity of individual regional distribution and relationship to clinical severity. Neuroscience. 1994;63:499-516.

144. Lewczuk P, Lelental N, Lachmann I, Holzer M, Flach K, Brandner S, et al. Non-phosphorylated Tau as a potential biomarker of Alzheimer's disease: analytical and diagnostic characterization. J Alzheimer's Dis. 2017;55(1):159-70.

145. Ermann N, Lewczuk P, Schmitz M, Lange P, Knipper T, Goebel S, et al. CSF nonphosphorylated Tau as a biomarker for the discrimination of AD from CJD. Ann Clin Transl Neurol. 2018;5(7):883-7.

146. Foiani MS, Cicognola C, Ermann N, Woollacott IOC, Heller C, Heslegrave AJ, et al. Searching for novel cerebrospinal fluid biomarkers of tau pathology in frontotemporal dementia: an elusive quest. J Neurol Neurosurg Psychiatry. 2019;90(7):740-6.

147. Parnetti L, Cicognola C, Eusebi P, Chiasserini D. Value of cerebrospinal fluid alpha-synuclein species as biomarker in Parkinson's diagnosis and prognosis. Biomark Med. 2016;10:35-49.

148. Eusebi P, Giannandrea D, Biscetti L, Abraha I, Chiasserini D, Orso M, et al. Diagnostic utility of CSF alpha-synuclein species in Parkinson's disease: protocol for a systematic review and meta-analysis. BMJ Open. 2016;6:e011113.

149. Twohig D, Nielsen HM. Alpha-synuclein in the pathophysiology of Alzheimer's disease. Mol Neurodegener. 2019;14:23.

150. Oeckl P, Metzger F, Nagl M, von Arnim CA, Halbgebauer S, Steinacker P, et al. Alpha-, beta-, and gamma-synuclein quantification in cerebrospinal fluid by multiple reaction monitoring reveals increased concentrations in Alzheimer's and CreutzfeldtJakob disease but no alteration in synucleinopathies. Mol Cell Proteom. 2016;15:3126-38.

151. Slaets S, Vanmechelen E, Le Bastard N, Decraemer H, Vandijck M, Martin JJ, et al. Increased CSF alpha-synuclein levels in Alzheimer's disease: correlation with tau levels. Alzheimer's Dement. 2014;10:S290-S298298.

152. Andreasson U, Blennow K, Zetterberg H. Update on ultrasensitive technologies to facilitate research on blood biomarkers for central nervous system disorders. Alzheimer's Dement (Amst). 2016;3:98-102.

153. Florentinus-Mefailoski A, Safi F, Marshall JG. Enzyme linked immuno mass spectrometric assay (ELIMSA). J Proteom. 2014;96:343-52.

154. Andreasson U, Portelius E, Pannee J, Zetterberg H, Blennow $\mathrm{K}$. Multiplexing and multivariate analysis in neurodegeneration. Methods. 2012;56:464-70. 
155. Lewczuk P, Kornhuber J, Vanmechelen E, Peters O, Heuser I, Maier W, et al. Amyloid beta peptides in plasma in early diagnosis of Alzheimer's disease: a multicenter study with multiplexing. Exp Neurol. 2010;223(2):366-70.

156. Kułakowska A, Mroczko B, Mantur M, Lelental N, Tarasiuk J, Kapica-Topczewska K, et al. Multiplexing analysis of the polyspecific intrathecal immune response in multiple sclerosis. Methods. 2012;56(4):528-31.

157. Lewczuk P. The pros and cons of multiplexing: a guest-editor's introduction. Methods. 2012;56(4):461-3.

158. Rissin DM, Kan CW, Campbell TG, Howes SC, Fournier DR, Song L, et al. Single-molecule enzyme-linked immunosorbent assay detects serum proteins at subfemtomolar concentrations. Nat Biotechnol. 2010;28(6):595-9.

159. Lewczuk P, Ermann N, Andreasson U, Schultheis C, Podhorna J, Spitzer P, et al. Plasma neurofilament light as a potential biomarker of neurodegeneration in Alzheimer's disease. Alzheimers Res Ther. 2018;10(1):71.

160. Georganopoulou DG, Chang L, Nam JM, Thaxton CS, Mufson EJ, Klein WL, et al. Nanoparticle-based detection in cerebral spinal fluid of a soluble pathogenic biomarker for Alzheimer's disease. Proc Natl Acad Sci USA. 2005;102(7):2273-6.

161. Chieh JJ, Yang SY, Jian ZF, Wang WC, Horng HE, Yang HC, et al. Hyper-high-sensitivity wash-free magnetoreduction assay on biomolecules using high-Tc superconducting quantum interference devices. J App Phys. 2008;103:014703.

Publisher's Note Springer Nature remains neutral with regard to jurisdictional claims in published maps and institutional affiliations.

\section{Affiliations}

\section{Piotr Lewczuk ${ }^{1,2}\left(\right.$ D $\cdot$ Marta Łukaszewicz-Zając ${ }^{3} \cdot$ Piotr Mroczko $^{4} \cdot$ Johannes Kornhuber $^{1}$}

Piotr Lewczuk

Piotr.Lewczuk@uk-erlangen.de

1 Lab for Clinical Neurochemistry and Neurochemical Dementia Diagnostics, Department of Psychiatry and Psychotherapy, Universitätsklinikum Erlangen, Friedrich-Alexander Universität Erlangen-Nürnberg, Schwabachanlage 6, 91054 Erlangen, Germany
2 Department of Neurodegeneration Diagnostics, Medical University of Białystok, Białystok, Poland

3 Department of Biochemical Diagnostics, Medical University of Białystok, Białystok, Poland

4 Department of Criminal Law and Criminology, Faculty of Law, University of Białystok, Białystok, Poland 